\title{
Suppression of angiotensin II stimulated responses in aortic vascular smooth muscle cells of experimental cir- rhotic rats
}

\author{
Zhang Ru ${ }^{1,2}$, Guo Liang Wang ${ }^{2, *}$, Pi Li Zhang ${ }^{2}$, Ying \\ $\mathrm{Xiong}^{1}$, Wen Bo Zhang ${ }^{1}$, Xing Peng Wang ${ }^{2}$, De Ling \\ YIN $^{1}$, QING JING ${ }^{1 *}$ \\ 1 Shanghai Institute of Cell Biology, Chinese Academy of \\ Sciences, 320 Yueyang Road, Shanghai 200031, China \\ ${ }^{2}$ Department of Gastroenterology, Shanghai First People's \\ Hospital, Shanghai Medical University, 80 Wu Jin Road, \\ Shanghai 200080, China
}

\begin{abstract}
Functional responses to angiotensin II (AT-II) were determined in aortic vascular smooth muscle cells (VSMCs) from experimental cirrhotic rats. Our data showed that AT-II-stimulated extracellular acidification rate (ECAR), which was measured by Cytosensor microphysiometry, was significantly reduced in the aortic VSMCs from the cirrhotic rats as compared to those from the control animals. The ability of AT-II to promote formation of inositol phosphates, the second messenger produced by the activation of Gq-coupled receptors, was also considerably suppressed in the cirrhotic VSMCs. Furthermore, the maximal p42/44 MAPK phosphorylation stimulated by ATII was significantly reduced in the cirrhotic VSMCs in contrast to that in the normal VSMCs. Taken together, our data clearly demonstrated that the functional responses to AT-II was severely suppressed in aortic VSMCs in cirrhosis, indicating the impairment of general Gq-coupled receptor signaling and subsequent biological function in the cirrhotic VSMCs.
\end{abstract}

\footnotetext{
* Corresponding Authors. Fax: 0086-21-64718563. E-mail: recbio@sunm.shcnc.ac.cn Abbreviations used are: AT-II, angiotensin II; VSMCs, vascular smooth muscle cells; ECAR, extracellular acidification rate; MAPK, mitogen-activated protein kinase; DMEM, Dulbecco's modified Eagle's medium; FCS, fetal calf serum; SDS, sodium dodecyl sulfate.
} 
Suppression of II responses in cirrhotic VSMCs

Key words: Angiotensin II, aortic vascular smooth muscle cells, cirrhosis, receptor responses.

\section{INTRODUCTION}

Liver cirrhosis is often complicated by hyperdynamic circulation, which is characterized by a decrease in arterial blood pressure and peripheral vascular resistance and an increase in cardiac output and splanchnic blood flow[1]. These haemodynamic disturbances are proposed to contribute to the development of portal hypertension, retention of sodium and water, ascites formation and correlate with prognosis of liver cirrhosis[2]. It has been suggested that primary arterial vasodilation may induce this hyperdynamic circulation[3]. But the underlying mechanisms are not fully understood. Vascular hyporesponsiveness to major endogenous vasoconstrictors, such as AT-II, vasopressin, a1-adrenoceptor agonists, and endothelin-1, have been claimed as important causative factors in arterial vasodilation. All of their productions are elevated whereas their effects are reduced in cirrhosis. Since these substances must bind to their specific membrane receptors (which are all Gq protein-coupled receptors) on VSMCs to induce vasoconstriction[4], one hypothesis is that hyporeactivity may be due to impairment of either receptors or post-receptor signaling[5].

The vasopressor hormone AT-II is an important modulator of vascular tone and also a growth factor in VSMCs. Binding of AT-II to its receptor leads to stimulation of phosphatidylinositol-specific phospholipase $\mathrm{C}$ activity through the activation of $\mathrm{G}$ protein and generation of second messenger inositol triphosphate and diacylglycerol, which are involved in intracellular $\mathrm{Ca}^{2+}$ mobilization and protein kinase $\mathrm{C}$ activation, respectively. Angiotensin II also can promote $\mathrm{Na}^{+} / \mathrm{H}^{+}$exchange and stimulate MAPK, by which intracellular calcium concentration and cellular metabolic rate are enhanced[6]. It should be noted that activation of these pathways has been associated with VSMCs contraction, increased cell proliferation, and protein synthesis, and impairment of these pathways may induce the vascular hyporesponsiveness in cirrhosis. The aim of the present study was to investigate functions of AT-II receptor-mediated signaling pathway in VSMCs of experimental liver cirrhotic rats.

\section{MATERIALS AND METHODS}

\section{Animal models and preparation of aortic VSMCs}

Cirrhosis was induced in male Sprague-Dawley rats weighting 300-350 g by bile-duct ligation as previously described[7]. Thoracic aortas were resected from rats 4-5 w after operation. This delay was necessary for the development of secondary biliary cirrhosis.

Rat thoracic aortic VSMCs were isolated and cultured by a modification of the procedures described elsewhere[8]. Briefly, under sterile conditions, descending thoracic aorta was resected from rats and washed in D-Hank's balanced salt solution. After removing adherent fat and connective tissues, vessels were then opened longitudinally and endothelial cells were removed by blunt scrape. After minced into 1-mm pieces, aortas were placed in fresh D-Hank' s containing 
collagenase (type I, $1 \mathrm{mg} / \mathrm{ml}$ ) (Sigma), elastase (type I, $0.5 \mathrm{mg} / \mathrm{ml}$ ) (Sigma), incubated for 2.0-2. $5 \mathrm{~h}$ at $37^{\circ} \mathrm{C}\left(5 \% \mathrm{CO}_{2}, 95 \%\right.$ air $)$ with agitation at 30 -min intervals until single-cell suspension was obtained. Then the cells were washed with Dulbecco's modified Eagle's medium (DMEM) (GIBCOBRL) and seeded in DMEM containing $10 \%$ fetal calf serum (FCS). Cell viability were assessed by trypan blue exclusion. Characterization of VSMCs isolate (positive for smooth muscle-specific aactin and negative for factor V) was performed on primary cultures.

\section{Cytosensor microphysiometry}

ECAR which presents the $\mathrm{Na}^{+} / \mathrm{H}^{+}$exchange function and cellular metabolic rate was measured with the sillicon-based light addressable potentiometer Cytosensor Microphysiometor (Molecular Device) as described previously[9]. Aortic VSMCs were seeded at $1 \times 10^{5}$ cells/capsule cup in DMEM. After incubated for $12 \mathrm{~h}$ at $37{ }^{\circ} \mathrm{C}$ in $5 \% \mathrm{CO}_{2}$, the cups were mounted into the sensor chamber. Low-buffered, carbonate-free DMEM with $0.1 \%$ bovine serum albumin was used as running buffer and ECAR data were measured every $90 \mathrm{~s}$. Cells were exposed to AT-II (Sigma) diluted into running buffer $(0.1 \mathrm{ml} / \mathrm{min})$ for $335 \mathrm{~s}$ and the real-time effects on the ECAR were recorded. All basal ECAR was normalized to $100 \%$.

\section{Inositol phosphate assay}

Aortic VSMCs were seeded at $3 \times 10^{5}$ cells/well in 12 -well multidishes in DMEM with $10 \%$ FCS. After attachment, cells were labelled with fresh DMEM containing myo- $\left[{ }^{3} \mathrm{H}\right]$ inositol $(1.0 \mu \mathrm{Ci} / \mathrm{ml})$ (Amersham Pharmacia Biotech) and $10 \%$ FCS. $24 \mathrm{~h}$ after labeling, the cells were rinsed with assay medium (serum-free DMEM with $20 \mathrm{mM} \mathrm{LiCl}$ ), followed by incubation at $37{ }^{\circ} \mathrm{C}$ for $0.5-1 \mathrm{~h}$ in $0.5 \mathrm{ml}$ of assay medium with varying concentrations of AT-II. Inositol phosphate production was estimated by determining the ratio of $\left[{ }^{3} \mathrm{H}\right]$ inositol phophates to $\left[{ }^{3} \mathrm{H}\right]$ inositol plus $\left[{ }^{3} \mathrm{H}\right]$ inositol phosphates[18].

\section{p42/44 MAPK phosphorylation detected by Western blotting}

AT-II stimulated -p42/44 MAPK phosphorylation was measured with Western blotting assay as described previously[11]. Briefly, after making quiescence with DMEM containing $0.5 \%$ serum for $24 \mathrm{~h}$, aortic VSMCs were treated with AT-II at $37{ }^{\circ} \mathrm{C}$ in serum-free DMEM. Then cells were lysed with the sample buffer containing $62.5 \mathrm{mM}$ Tris- $\mathrm{HCl}, 2 \%$ (w/v) sodium dodecyl sulfate (SDS), $10 \%$ glycerol, and $50 \mathrm{mM}$ dithiothreitol, $\mathrm{pH}$ 6.8. Protein concentrations were determined by the modified Lowry method. The samples were subjected to $10 \%$ SDS-polyacrylamide gel electrophoresis and then transferred to nitrocelluose membranes. After blocked with $5 \%$ bovine serum albumin, the membranes were blotted with the primary antibodies (the rabbit polyclonal anti-phospho or anti-total p42/44 MAPK) (New England Biolabs Inc) and the secondary antibody (HRP-conjugated anti-rabbit) (GIBCO-BRL) and then detected by enhanced chemiluminescence detection system (Amersham Pharmacia Biotech) according to the manufacturer's instructions. For repeated immunoblotting, membranes were stripped in $62.5 \mathrm{mM}$ Tris-HCl, $2 \%$ $\mathrm{SDS}$, and $0.1 \mathrm{M} \mathrm{2-mercaptoethanol} \mathrm{for} 30 \mathrm{~min}$ at $50{ }^{\circ} \mathrm{C}$.

\section{Statistical analysis}

Results of the experiments were expressed as means \pm SD. Student's t test was used for the statistical analysis of the results. $p$ values of $<0.05$ were considered to be significant.

\section{RESULTS}

\section{AT-II-stimulated peak ECAR in aortic VSMCs}

Although it has been demonstrated that Gq-coupled receptor about can mediate their agonist-stimulated extracellular acidification rate (ECAR), but there is no report about 
Suppression of II responses in cirrhotic VSMCs

whether AT-II can effectively enhance ECAR, especially in aortic VSMCs. In this study, our data (Fig 1) showed that AT-II could stimulate ECAR in concentration-dependen manner in normal aortic VSMCs with the maximal peak value of about $150 \%$ and an $\mathrm{EC}_{50}$ of 5.5 $\pm 0.34 \mathrm{nM}$ (Fig 1). In contrast, AT-II-stimulated peak ECAR was significantly reduced to around $110 \%$ (Fig 1 ) in the aortic VSMCs from the cirrhotic rats though the $\mathrm{EC}_{50}$ was unchanged $(4.25 \pm 0.30 \mathrm{nM})$. This suggests that AT-II receptor signaling pathway is severely impaired in the aortic VSMCs in cirrhosis.

Fig 1.

AT-II-stimulated peak ECAR in aortic VSMCs. Cells were stimulated with different concentrations of AT-II as indicated. The maximal peak value of AT-II response in normal aortic VSMCs was about $150 \%$ with an $\mathrm{EC}_{50}$ of $5.5 \pm 0.34 \mathrm{nM}$ and that in the cirrhotic VSMCs was $110 \%$ with an $\mathrm{EC}_{50}$ of $4.25 \pm 0.30 \mathrm{nM}$. Data were means $\pm \mathrm{SD}$ from two independent experiments.

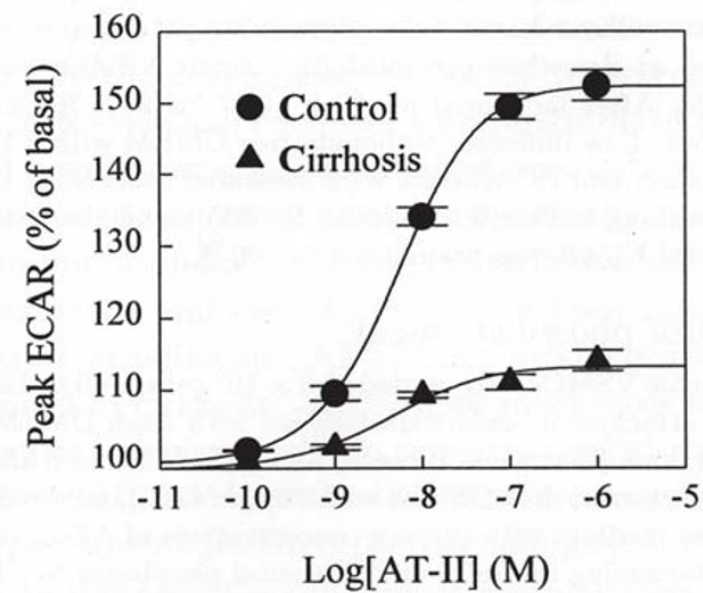

\section{AT-II-promoted inositol phosphate formation in aortic VSMCs}

Measurement of inositol phosphate formation has been used as a standard method to assay functions of Gq-coupled receptors. As shown in Fig 2, AT-II dose-dependently promote inositol phosphate formation in the normal aortic VSMCs with the maximal activation of nearly 10 folds above the basal. However, the ability of AT-II to promote inositol phosphate formation was significantly suppressed in the cirrhotic VSMCs at all concen-

Fig 2.

AT-II-promoted inositol phosphate formation in aortic VSMCs. Cells were stimulated for $30 \mathrm{~min}$ with different concentrations of AT-II as indicated, and inositol phosphates formation was measured in the normal and cirrhotic aortic VSMCs as described in "Materials and Methods". Data were means \pm SD from four independent experiments.

$* \mathrm{p}<0.05$ and $* * \mathrm{p}<0.01$ as compared to the control at the same concentration.

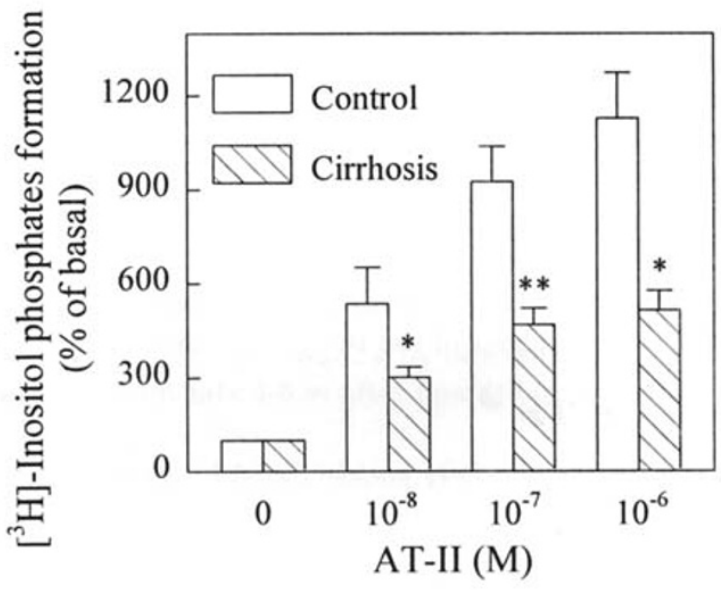


trations measured (10-9 M, 10-8 M, and 10-7 M). The result further supports the suggestion that AT-II receptor signaling pathway is indeed severely damaged in the aortic VSMCs.

\section{Stimulation of p42/44 MAPK phosphorylation by AT-II}

It has been established that p42/44 MAPK are activated by phosphorylation of threonine and tyrosine[12], and the phosphorylation of p42/44 MAPK has been widely used to indicate their activation. Currently, measurement of p42/44 MAPK phosphorylation was achieved by Western blot analysis using the specific anti-phospho p42/44 MAPK antibody which reacts with phosphorylated p42/44 MAPK. Our studies showed that the maximal P42/44 MAPK phosphorylation stimulated by AT-II was achieved at $10^{-7} \mathrm{M}$ within 5-10 min in aortic VSMCs (data not shown). In all subsequent experiments, therefore, cells were stimulated for 5 min at $10^{-7} \mathrm{M}$ by AT-II. As shown in Fig 3, exposure of normal aortic VSMCs to AT-II led to about 8-fold increase in p42/44 MAPK phosphorylation, but the response of the cirrhotic VSMCs to AT-II was only around 3 fold innease above the basal value. AT-II stimulation of p42/44 MAPK phosphorylation was significantly different between the two groups $(\mathrm{p}<0.01)$. The total amount of $\mathrm{p} 42 / 44$ MAPK did not change during treatment in both groups.

A

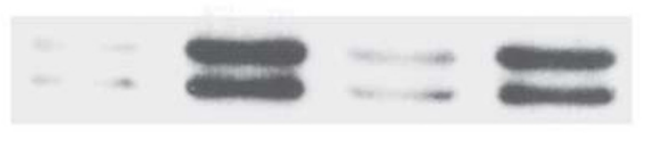

B

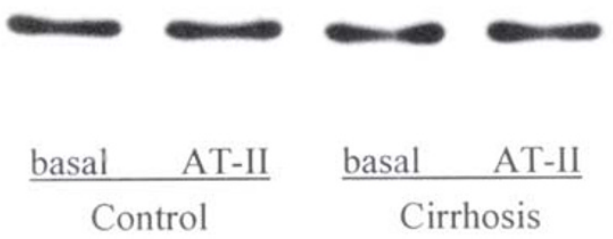

C

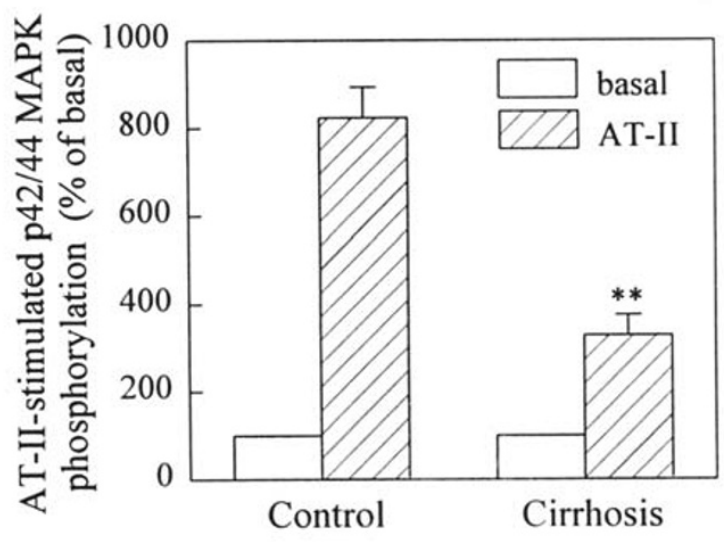

Fig 3.

Stimulation of p42/44 MAPK phosphorylation by AT-II in aortic VSMCs. Cells were stimulated with $10^{-7} \mathrm{M}$ AT-II for $5 \mathrm{~min}$, and then lysed as described in "Materials and Methods”. Fraction of cell lysates were subjected to Western blot analysis. A. Detection of phosphorylation of p42/44 MAPK in VSMCs by anti-phospho p42/44 MAPK antibody. B. Detection of total p42/44 MAPK in VSMCs by anti-total p42/44 MAPK antibody. C. Quantification of phosphorylation of p42/44 MAPK in VSMCs by densitometry. Data were means \pm SD from three independent experiments.

** $\mathrm{p}<0.01$ as compared to the AT-II stimulated in the control. 
Suppression of II responses in cirrhotic VSMCs

\section{DISCUSSION}

In vitro cultured VSMCs retain all the characteristics of their in vivo counterparts, including those of the membrane receptors and their pathways required to transduce agonist responses, and the cirrhotic VSMCs cultured in vitro will keep their typical hyporesponsiveness at least in sixteen generation[13]. The earlier studies showed that the signaling pathways of either Gs or Gi and the downstream adenylyl cyclase system were severely suppressed in cirrhosis[14]. In this study, we used several different technologies such as biochemical assays for the second messenger production and MAPK activation, and cytosensor microphysiometry for celluar metabolic rate to test the function of Gq-coupled AT-II receptor signaling pathway. First, binding of AT-II to its receptor leads to the activation of phospholipase $\mathrm{C}$, an upstream effector in Gq protein signaling pathway, which is known to induce the generation of inositol triphosphate and diacylglycerol. Second, phosphorylation of p42/44 MAPK, a downstream effector in G protein pathway, can transduce extracellular signal into nuclear to regulate cell proliferation and differentiation. The third, activation of $\mathrm{G}$ protein can also affect the activities of $\mathrm{Na}^{+} / \mathrm{H}^{+}$exchanger and iron channel located in plasma membrane to change intracellular $\mathrm{pH}$ value and iron concentration. Those three indexes measured in our study, which represent the important function of $\mathrm{G}$ protein pathway in different aspects, were significantly reduced in cirrhotic VSMCs and suggested the general impairment of Gq-coupled receptor signaling pathway in cirrhosis.

It is worth notice that though the maximal response to AT-II was significantly reduced in the cirrhotic VSMCs, the EC50 of AT-II response curve was unchanged, consistent with the previous report which showed that the AT-II dissociation constant was little altered under the similar conditions[13]. The same report also showed that the number of receptors on the surface of cirrhotic VSMCs was higher than on control VSMCs. The present investigation, taken together, indicates that the impairment of AT-II signaling pathway likely occurs at post-receptor level.

The molecular mechanism underlying the dysfunction of AT-II signaling pathway in cirrhosis is unclear. It has been shown that major endogenous vasoconstrictors, such as AT-II, are elevated in cirrhosis[15]. The persistent exposure of VSMCs to the elevated AT-II may thus lead to desensitization and down-regulation of AT-II signaling pathway, as demonstrated in many cases of other $\mathrm{G}$ protein-coupled receptor signaling systems. The lower responsiveness to AT-II will induce more production of AT-II, which in turn makes more damage to AT-II signaling system. The impairment of AT-II signaling pathway will consequently prevent cell growth, proliferation, protein synthesis, and vascular constriction in cirrhotic VSMCs. The current study may thus suggest using of antagonists of AT-II receptor to counteract the elevated AT-II so as to ameliorate the hyperdynamic circulation status in cirrhosis, just as those antagonists of adrenoceptors which have been used in clinics. 


\section{ACKNOWLEGEMENTS}

This work was supported by the National Natural Science Foundation of China (No: 39600157), Chinese Academy of Sciences, the German Max-Planck Society, and Shanghai Health Bureau (No: 964Y12). The authors wish to thank Dr. Gang PEI for his comment and review of this manuscript, Shun Mei XIN, Zhe ZHANG, Kun LING, Jian ZHAO and Guo Bing BAO for their technical assistance.

\section{REFERENCES}

[1] Schrier RW. Peripheral arterial vasodilation in cirrhosis and impaired mineralocorticoid escape. Gastroenterology 1992; 102(6):2165-8.

[2] Vallance P, Moncada S. Hyperdynamic circulation in cirrhosis: a role for nitric oxide? The Lancet 1991; 337:776-8.

[3] Schrier RW, Arroyo V, Bernardi M, Epstein M, Henriksen JH, Rodes J. Peripheral arterial vasodilation hypothesis: a proposal for the initiation of renal sodium and water retention in cirrhosis. Hepatology 1988; 8:1151-7.

[4] Berridge MJ. Inositol triphosphate and calcium signalling. Nature 1993; 361:315-25.

[5] Murray BM, Paller MS. Decreased pressor reactivity to angiotensin II in cirrhotic rats. Evidence for a post-receptor defect in angiotensin action. Circ Res 1985; 57(3):424-31.

[6] Boston DR, Koyama T, Rodriguez Larrain J, Zou A, Su Z, Barry WH. Effects of angiotensin II on intracellular calcium and contracture in metabolically inhibited cardiomyocytes. J Pharmacol Exp Ther 1998; 285(2):716-23.

[7] Lee SS, Girod C, Braillon A, Hadengue A, Lebrec D. Hemodynamic characterization of chronic bile duct-ligated rats: effect of pentobarbital sodium. Am J Physiol 1986; 251(2 Pt 1):G176-80.

[8] Jing Q, Xin SM, Cheng Zhi Jie et al. Activation of p38 MAPK by Oxidized LDL in Vascular Smooth Muscle Cells: Mediation via Pertussis Toxin-sensitive G Proteins and Association with Oxidized LDL-induced Cytotoxicity. Circ Res 1999; 84:(in press).

[9] Ling K, Ma L, Pei G. Differential efficacies of kappa agonists to induce homologous desensitization of human kappa opioid receptor. Neurosci Lett 1998; 240(1):25-8.

[10]Fan GH, Zhou TH, Zhang WB, Pei G. Suppression of phospholipase C blocks Gi-mediated inhibition of adenylyl cyclase activity. Eur J Pharmacol 1998; 341(2-3):317-22.

[11]Lou LG, Zhang Z, Ma L, Pei G. Nociceptin/orphanin FQ activates mitogen-activated protein kinase in Chinese hamster ovary cells expressing opioid receptor-like receptor. J Neurochem 1998; 70(3): 1316-22.

[12]Rossomando AJ, Sanghera JS, Marsden LA, Weber MJ, Pelech SL, Sturgill TW. Biochemical characterization of a family of serine/threonine protein kinases regulated by tyrosine and serine/ threonine phosphorylations. J Biol Chem 1991; 266(30):20270-5.

[13]Tazi KA, Moreau R, Cailmail S, Gadano A, Trombino C, Lebrec D. Altered growth and lack of responsiveness to angiotensin II in aortic vascular smooth muscle cells from cirrhotic rats. Gastroenterology 1997; 112(6):2065-72.

[14]Ma Z, Miyamoto A, Lee SS. Role of altered beta-adrenoceptor signal transduction in the pathogenesis of cirrhotic cardiomyopathy in rats. Gastroenterology 1996; 110(4):1191-8.

[15]Blendis LM. Circulation in liver disease. Transplant Proc 1993; 25:1741-3.

Received March-31-1999. Revised May-10-1999. Accepted May-26-1999. 